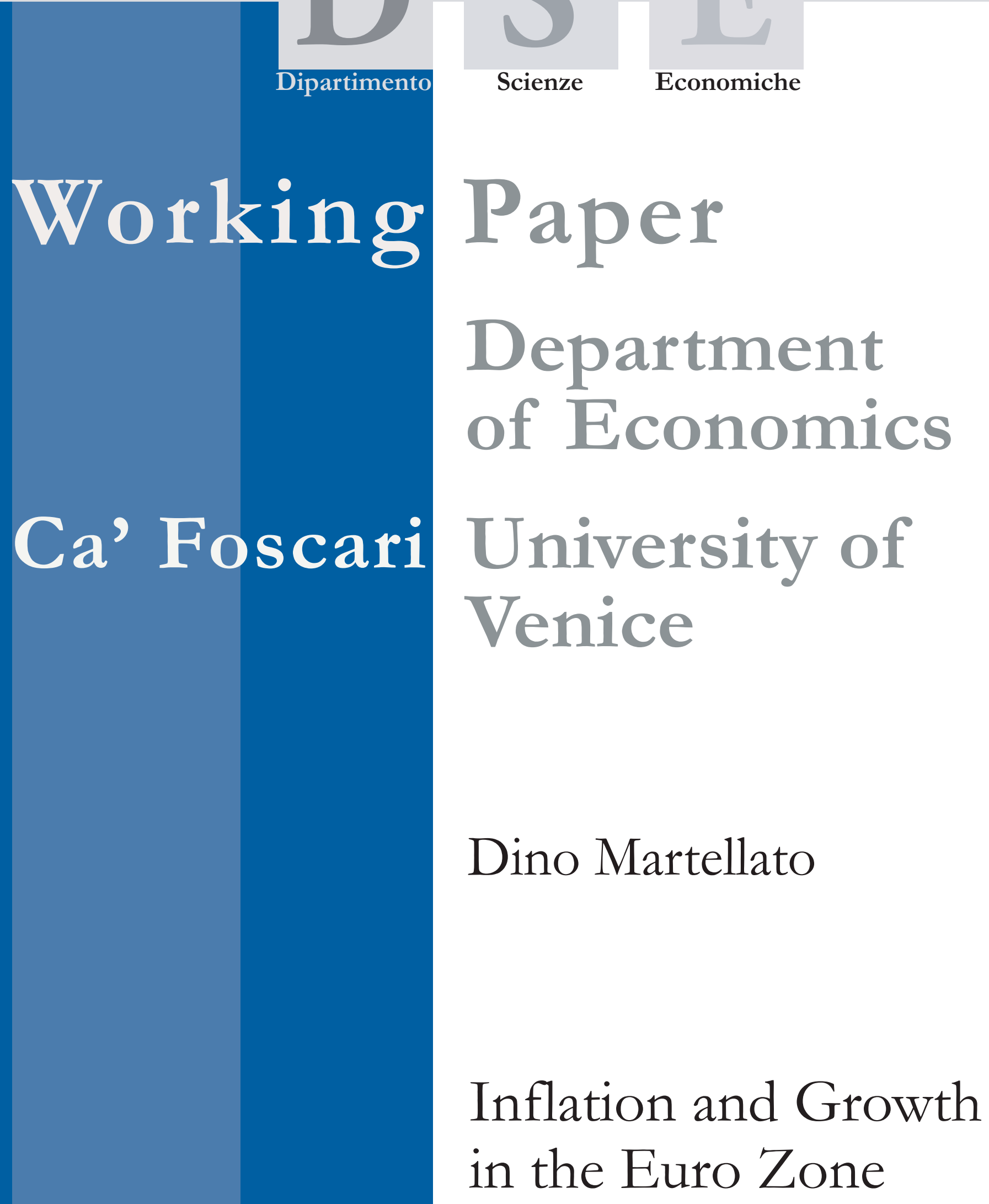




\title{
Inflation and Growth in the Euro Zone
}

\author{
Dino Martellato \\ Università Ca' Foscari di Venezia
}

First Draft: October 2006

\begin{abstract}
Although euro area-wide inflation was from 1999 to 2005 almost right, i.e. "close to balance, but below $2 \% "$, and although it combined with real growth as predicted by the long-run money demand equation in the euro area, the picture that emerges at country level is more scattered. Inside a monetary union, inflation divergences could be destabilizing and an excessive dispersion could be a problem, thus the scattered performance of the single members in terms of HICP inflation and real growth is an issue that the euro area governance is illprepared to manage. It may be of interest, therefore, to understand whether observed differences come from the money market or from the costs side or from the interaction between supply and demand when agents are forward looking. The paper sets out to ascertain whether the patterns of inflation and growth data observed in the twelve members and Slovenia compare to what is predicted by the long-run money demand equation in the euro area, the Balassa-Samuelson construct or the New Keynesian model.
\end{abstract}

\section{Keywords}

Inflation, stability, euro zone

\section{JEL Codes}

E12, E41, E52, E63

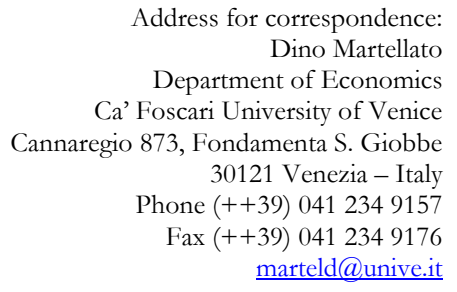

his Working Paper is published under the auspices of the Department of Economics of the Ca' Foscari University of Venice. Opinions expressed herein are those of the authors and not those of the Department. The Working Paper series is designed to divulge preliminary or incomplete work, circulated to favour discussion and comments. Citation of this paper should consider its provisional character.

The Working Paper Series is availble only on line (www.dse.unive.it/pubblicazioni) For editorial correspondence, please contact:wp.dse@unive.it
Department of Economics

Ca' Foscari University of Venice

Cannaregio 873, Fondamenta San Giobbe

30121 Venice Italy

Fax: ++390412349210 


\section{INFLATION AND GROWTH IN THE EURO ZONE}

\section{Two types of macroeconomic stability}

Macroeconomic stability is traditionally defined as the combination of stable consumption prices and a sustainable public borrowing position, with real output close to potential output, but it has often been argued that the concept of stability should encompass other dimensions: e.g. stable asset prices and a sustainable private borrowing position. In a monetary union such as EMU, in particular, stability should also be given a geographical dimension as stability requires convergence in inflation in member and accession countries. Macroeconomic stability is held to be a precondition for long term growth and also one of the main achievements of the EU in the pre-EMU phase. It is useful to understand whether EMU has been and will be able to deliver. As real growth is uneven across space, particularly in the euro zone and the enlarged EU, it is crucial to understand in which ways growth disparities feed inflation disparities.

In this paper we look at inflation and growth differentials in the euro zone from 1997 to 2005 and try to understand what available theories are able to account for the patterns in which inflation and growth combine in the euro zone countries. Section 2. focuses on the achievements of the euro zone as such, year-by-year, and of the single countries, on average. Section 3 focuses on the consequences of inflation disparities. Sections 4, 5 and 6 focus on the available theories and find that they offer different predictions about the relation between growth and inflation in the short run. The final section focuses on the differences across countries year-by-year and speculates about which theories are able to match the available evidence for the euro zone.

\section{The achievements since 1999}

The euro zone economy is managed with a common monetary policy and weekly coordinated national fiscal policies. A further characteristic feature of EMU is that while the decision making at the European Central Bank is based on an eclectic combination of economic and monetary analyses ${ }^{1}$, rather than on any known explicit rule (Papademos, 2006), the eleven national governments and their fiscal policies are subject to a strict rule (the Stability and Growth pact). It is also well known that while urging the EU Council of Economy and Finance Ministers to watch the actions of national governments, the ECB refuses to adhere to any explicit and known rule in its conduct. Since the introduction of the euro in 1999, the single

\footnotetext{
${ }^{1}$ Also known as the two pillars.
} 
member countries have not made concrete progress in the consolidation of public finances, and after the difficulties in the budget of the larger countries in the euro zone and the debate about the usefulness of the Stability pact they agreed to revise it in 2005. The new pact emphasizes the importance of total debt relative to that of net debt, but its enforcement appears to be softer than before. The ECB has interpreted the move as weakened fiscal discipline. While the ECB, which took control of the common monetary policy in 1999 has only been able to keep the inflation rate close to - but above - the target level from 2000 on (see Fig 1), it has done so by adopting a policy which has often been accused of being unduly rigid ${ }^{2}$.

When we come to the country level (Fig 2), we observe that average inflation rates ${ }^{3}$ are quite different: the most virtuous country is Germany (1.34\%) while the least virtuous is Greece (3.6\%), in the period 1997 - 2005. There are five countries which had an average inflation rate below the $2 \%$ limit: Germany 1.34\%, Austria 1,54\%, France 1.61\%, Belgium 1.79\% and Finland $1,51 \%$. Finland apart, these countries not only were in the $\mathrm{ERM}^{4}$ from the beginning (1979), but were also able to keep their currencies inside the narrow \pm 2.25 per cent band. Four EMU members (i.e. Portugal 2.79\%, Spain $2.82 \%$, Ireland $3.16 \%$ and Greece $3.6 \%$ ) had an average inflation rate above 2.5 per cent. Ireland excluded, the remaining three were latecomers in the ERM and had \pm 6 per cent, i.e. large bands. The three remaining countries (Italy 2.27\%, Luxembourg 2.36\% and Netherlands $2.46 \%$ ) have inflation rates between 2 and 2.5 per cent. All three were in the ERM from the start, but Italy left for a while after the 1992 crisis and for most of the time was in the large of \pm 6 per cent band. The differences in $E M U^{5}$ clearly reflect those experienced when the countries were in the ERM as if admission to the euro zone were ineffective. Even if one can acknowledge a certain degree of ability in delivering inflation convergence to the two systems, the ECB still has to face up to an unfinished job.

\footnotetext{
${ }^{2}$ It well known that macroeconomic stabilization in the euro zone not only lacks cooperation, but faces policy conflicts; see: Buti, Roeger and In’t Veld (2001).

${ }^{3}$ We have used annual average rate of changes in HICP, harmonized indexes of consumer prices, which are used by the ECB for monitoring inflation in the EMU. See:

http://epp.eurostat/.ec.europa.ec.

${ }^{4}$ The exchange rate mechanism (ERM) was the centrepiece of the European Monetary System which aimed to reduce exchange rate fluctuations and deliver monetary stability through a system of fixed but adjustable exchange rates.

${ }^{5}$ Busetti et al. (2006) arrived at the same results by applying unit root and stationarity tests to inflation data only.
} 
Fig.1 - Inflation and growth in the euro zone, 1997-2005

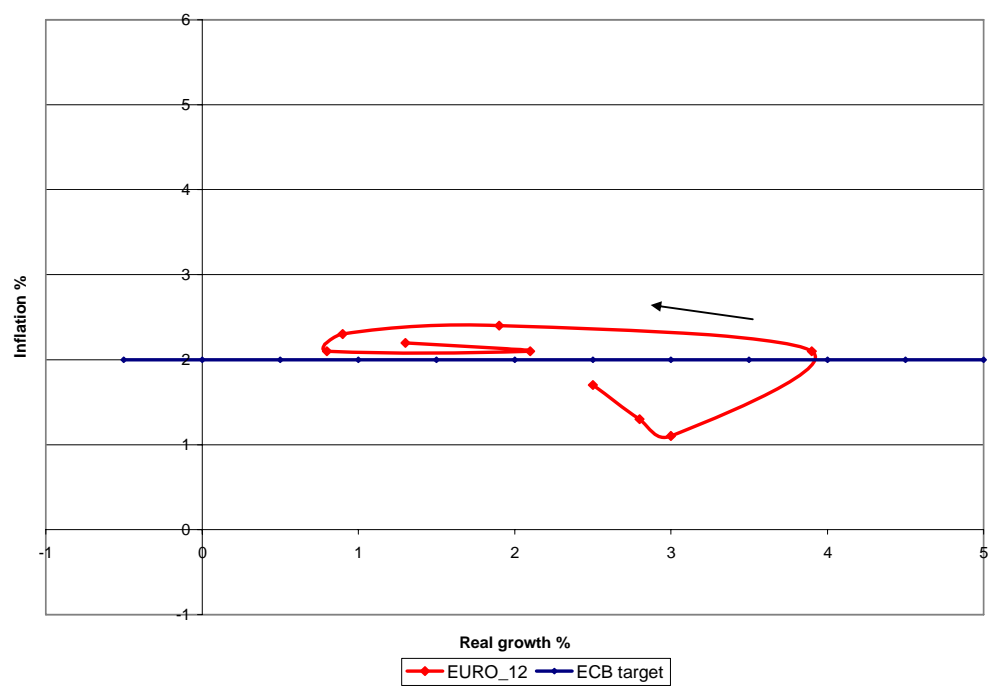

Fig. 2 - Inflation and growth in the euro zone, country averages (1997- 2005)

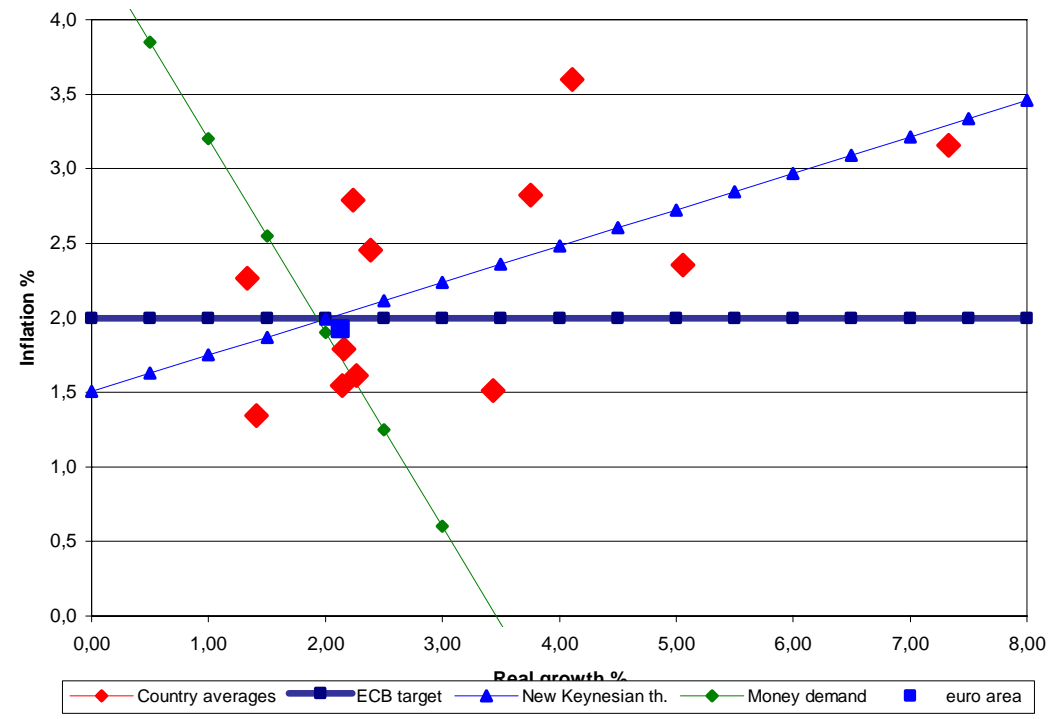

It is also interesting to consider real growth ${ }^{6}$. The dispersion in real growth rates is clearly higher than that in inflation rates. In terms of average rates in the euro zone and during the whole period 1997-2005, however, real growth is very close to inflation. Fig. 2 shows that the euro zone as such is close to 2 per cent inflation and 2 per cent real growth (actually 1.92 per cent inflation and 2.13 per cent growth). But if we stick to the period starting 1999, inflation is 2.04 per cent and growth 1.99 per cent. Fig 2 offers the basis for the central point dealt with in this paper, namely the

${ }^{6}$ See: http://epp.eurostat/.ec.europa.ec. 
combined performance in terms of inflation and growth and the relation between the two indicators. From 1997 to 2005, growth rates in the euro zone ranged from $1.33 \%$ to $7.33 \%$ while inflation rates spanned the $1.34 \%$ $3.6 \%$ range. The figures in Fig. 2 beg for an explanation, and the ascending straight line clearly offers a possible one. New Keynesian theory offers a well-known explanation for the positive relation between real growth and inflation as it posits that, in the short run and with a given expected inflation rate, an increase in output growth implies an higher rate of increase in costs and prices - a prediction that seems to fit the statistical evidence as summarized by the ascending line in Fig. 2. By regressing average inflation rates on average growth rates, we get: $p=1.5+0.24 \mathrm{~g}$, i.e. the ascending straight line.

This is not the whole story, however, as the analysis should be carried out at national level because the relation between output and prices offered by any New-Keynesian theory must reflect the intrinsic characteristics of markets in the national economy. EMU still seems to be a composite economic system to be analysed as a single economic system in a New Keynesian framework. There are, furthermore, other theories regarding the relation between growth and inflation that are worth considering. Take the horizontal line drawn at 2 per cent in Fig. 2. The line is the upper limit for inflation and thus represents not only the ECB target rate for the euro zone, but something that it assumes to be feasible in theory and in practice. This is why the limit can also be considered the virtual target for the inflation rate in single countries. Although the ECB does consider the inflation rates in single countries as something it cannot and should not target directly, it should be made feasible by national adjustment mechanisms. Furthermore, when differences in inflation rates are persistent and large, the ECB cannot be confident about its ability to deliver the proper policy everywhere in the euro zone. Inflation convergence, indeed, was and still is - one of the convergence criteria for membership of EMU and would be difficult to accept the ECB as being unable to keep on the same track as the single national central banks were able to do before becoming members. As there are other different theories concerning the relation between real growth and inflation, we must address the question in a more systematic way from both the economic and empirical points of view and in the next paragraph we start by summarizing the other, more compelling, arguments that make inflation differences a problem for the monetary union.

\section{The consequences of inflation disparities}

Between real output and inflation there is a circular relation and nobody questions the assumption that in the long run growth is negatively affected by the average rate of inflation as high inflation impairs the proper 
working of the price mechanism ${ }^{7}$ (Barro, 1996). From this point of view, it pays to adhere to an exchange rate mechanism such as the ERM or to a monetary union like EMU if it helps to reduce exchange rate fluctuations and inflation. In the short run, however, the relation between growth and inflation is more complex, particularly in a monetary union. Asymmetric shocks, differences in the economic structure of the different economies, lack of convergence between countries, or plain mismanagement are problems in a monetary union. The common monetary policy, which above was assumed to deliver advantages to members, could become destabilizing which is a particularly serious problem if there is not enough room for fiscal policy stabilization.

To look into the relation between growth and inflation it is helpful to make a distinction between the relationship going from real output to inflation and that going in the opposite direction. As for the latter, there are three basic mechanisms at work. The first deals with the real interest rate, the second goes through the real exchange rate, while the third involves the level of real wages. In a monetary union, these mechanisms deal with the implications of the common monetary policy on the performance of the real economy in the single member countries ${ }^{8}$.

As there are differences in the harmonized inflation rates across EMU, it is hardly surprising that consensus forecasts regularly show that expectations about inflation are also different. As the real interest rate in a particular country is the difference between the common short-term interest rate and the expected inflation rate in the same country: $i-p_{i}^{e}$ different expectations bear differently upon real interest rates across EMU. A country whose domestic inflation rate is permanently above the average, $p_{i}-p>0$, will enjoy a lower than average real interest rate because the expected domestic inflation rate will be higher than the average: $p_{i}^{e}-p^{e}>0$, notwithstanding the ECB target rate and its assessment of the area-wide expected inflation rate. Therefore, the difference $i-p_{i}^{e}<i-p^{e}$ fuels real demand where demand and inflation are higher than the average.

With a permanently high inflation rate, a country is normally less competitive and its net demand will be lower. The third mechanism works through real wages and has two distinct components. On one side, a higher inflation rate helps stabilization as it lowers real wages, thus reducing the impact of nominal rigidities. But, on the other side, there are the effects on

\footnotetext{
${ }^{7}$ Barro (1996), for instance, has verified that this is true in a large sample of countries for the period going from 1960 to 1990.

8 The inflation gap is the difference between the inflation rate in country $i$ and the euro zone rate as $: p_{i}-p$ and the output gap is the difference between the effective real growth rate and potential real growth rate by: $g_{i}-\bar{g}_{i}$.
} 
income distribution and thus on demand: lower income to workers would imply lower internal demand, but it could end up by boosting profits. The equity market could benefit, thus producing a wealth effect on consumption as well as having a positive effect on investment.

Furthermore, as real demand in larger economies is normally less dependent on foreign demand than is the case in smaller ones, the real interest and the real wage effects are likely to dominate the exchange rate effect in the larger economies and vice versa. The net result of inflation differentials on real demand clearly depends on the balance between the many different effects just mentioned and is thus a question which deserves an empirical test in each country.

All in all, there is a possibility that the ECB's monetary policy will end up not only delivering different stimuli to different member countries, but also permanently destabilizing effects from the demand side, if the differences in inflation are permanent and certain conditions are satisfied. This is worrying because the coordination between the different countries, the Commission and the ECB will be further impaired.

\section{Inflation disparities in the New Keynesian model}

Economic theory is much more uncertain about the link going from real demand towards inflation. There are basically three theories, offering very different predictions about the relation between real growth and inflation: the Keynesian theory, the monetarist construct and the structural model. The first, and perhaps the more general theory is what is now called the New Keynesian one, which considers both demand and supply and makes the inflation rate and the output gap mutually dependent when agents are forward looking. The monetarist model focuses only on money and real demand; the structural model deals only with the supply side.

Although it is a general equilibrium model of the economy with nominal rigidities as in the traditional Keynesian model, the New Keynesian model distinctly assumes that agents and the central bank are forwardlooking. It is the role of expectations and the presence of a monetary rule for the central bank, instead of the traditional money demand equation, that qualifies it as new ${ }^{9}$. The model dates back to the late Nineties (see e.g. : Clarida, Gali, Gertler, 1999) and in the literature it comes in different versions depending on whether the economy adjusts to current expectations of future inflation or past expectations of current inflation. The demand equation links the absolute level of the output gap to the real interest rate, the supply equation - basically an inflation-augmented Phillips curve,

\footnotetext{
${ }^{9}$ The more sophisticated formulations of this model encompass micro-foundations.
} 
determines the inflation rate and a Taylor monetary rule determines the nominal interest rate.

Although in the basic version of the theory (Clarida, Gali and Gertler, 1999) the economy is closed, it is useful to refer to the recent application by Angeloni and Ehrmann (2004) ${ }^{10}$ of such a model to the twelve open economies of the euro area. In the euro area there should ideally be twelve pairs of demand and supply equations plus one monetary rule, but because of the paucity of available data (they range from 1998:1 to 2003:1) AE were obliged to reduce the number of equations and parameters. Their $^{11}$ unique supply equation determines the inflation rate in the country $i$, namely:

$$
\begin{aligned}
& p_{i t}=c_{1}+\alpha_{1} p_{i t-1}+\left(1-\alpha_{1}\right) p_{i t+1}^{e}+\beta g a p_{i t}+\text { neer }_{i t}+\varepsilon_{1 i t} \\
& c_{1}=0 ; \alpha_{1}=0.461 ; \beta=0.087 ; \gamma=-0.075 .
\end{aligned}
$$

There are four demand equations, each one determining the output gap in the country $i$ on the base of one in four sets of parameters:

$$
\begin{aligned}
& \text { gap }_{i t}=c_{2}+\alpha_{3} \text { gap }_{i t-1}+\alpha_{4} \text { gap }_{i t+1}^{e}+\delta_{i}\left(r_{t-1}-p_{i t+1}^{e}\right)+\lambda_{i} \text { reer }_{i t}+\varepsilon_{i t} \\
& c_{2}=0.083 ; \alpha_{3}=0.515 ; \delta_{i}=-0.07 \text { or } \delta_{2}-0.147 ; \lambda_{i}=-0.052, \text { or } \lambda_{2}-0.209
\end{aligned}
$$

The model is closed by the money rule, which basically relates the interest rate to area-wide expected inflation and average output gap, namely:

$$
\begin{aligned}
& r_{t}=\rho r_{t-1}+(1-\rho)\left[\varphi_{p}\left(p_{t+k}^{e}-0.02\right)+\varphi_{y} g a p_{t}\right], \\
& \varphi_{p}=1.5,
\end{aligned}
$$

or, more simply:

$$
r_{t}=\varphi_{p} p_{t+1}^{e}
$$

The assumed area-wide output gap $\left(g_{a p}\right)$ obviously misrepresents the variety of country specific gaps which are likely to be present when the business cycles are not synchronized or when the shocks are asymmetrical. The ECB has always said that such a rule by no means represents its own strategy of intervention, even though its decisions obviously take inflation expectations into account. The ECB's own assessment of inflation expectations is anchored to the gap between the effective real money demand and long-run real money demand ${ }^{12}$ in the euro zone and other

\footnotetext{
${ }^{10}$ In what follows, Angeloni and Ehrmann will be briefly indicated with AE.

11 The estimates are those of Angeloni and Ehrmann (2004).

${ }^{12}$ It is the so-called "monetary overhang”, defined as the liquidity not accounted for by the cyclical state of the economy in terms of real demand and interest rates (ECB, 2004). See: http://ecb.int/pub/.
} 
variables, and its decisions on interest rates appear to be based on an eclectic analysis of the situation. However, some formal rule is always present in New Keynesian models not only because a formal rule is manageable, but also because some rules have proved to be able to track the profile of official interest rates. The money rule above is most often reduced to the simpler formulation: $r_{t}=\varphi_{p} p_{t+1}^{e}$ (equation 4 ). ${ }^{\cdot}$ This formulation implies a quick reaction to changes in expectations ( $\rho=0)$, and gives the parameter $\varphi_{p}$ a critical role. The Authors' findings indicate that when this parameter increases, the inflation rate deviates less from its long-term level and inflation differences are lower.

The supply equation assumes the current rate of inflation in each country, $p_{i t}$, as positively related to the level of real activity, i.e. the absolute output gap, and to the nominal effective exchange rate $\left(\right.$ neer $\left._{i t}\right)$. It further assumes the current inflation rate to be proportional to both the lagged inflation rate and the current expected inflation rate. When the lagged inflation rate parameter, $\alpha_{1}$, is high, there is inflation persistence as agents react less to current expectations of future inflation. When the output gap parameter $\beta$ is low, we say that there is rigidity in the markets as the inflation rate is moderately affected by the level of the output gap. The estimates show both persistence and rigidity $\alpha_{1}=0,461 ; \beta=0,087$ in the euro zone. The Authors' obvious conclusion is that inflation persistence is the factor propagating inflation differences, but the basic point appears to have been missed: why is inflation different across countries, if the monetary policy is the same?

It is easier to grasp the mechanics of the New Keynesian model if we use the schoolbook graphic representation of Fig. $3^{13}$ where the output gap in country $i$ ( $g_{i}-\bar{g}_{i}$, with $\bar{g}_{i}$ as potential growth) is assumed to be positive. The supply line has a positive slope in Fig. 3, Panel A, while the demand curve can be represented as the descending line in Fig. 3, Panel B. In their model for the euro area, AE assume that there are differences in the slope coefficients of the demand curve, thus admitting that monetary stimuli are passed differently across the different member countries, but they assume that there are no differences in the supply side. In particular, while there are no differences in the pass-through of import costs onto inflation $(\gamma)$, the Authors discriminate between countries as far as openness to trade is concerned. The monetary rule (equation 3), which calls for an increase in the nominal interest rate $\left(r_{t}\right)$ when the area-wide expected inflation rate $\left(p_{i t+1}^{e}\right)$ increases and when the area-wide output gap increases, appears as an ascending line in Fig. 3, Panel B. Consider now the case of an adverse and symmetric supply shock ( $\varepsilon_{1 i t}>0$, everywhere). The shock shifts the supply schedule upwards in Fig. 3, thus yielding an increase in the inflation rate at

${ }^{13}$ Fig. 3 represents a general case, not the AE model. 
the initial output gap in country i. To understand why the symmetric shock could lead to asymmetric effects, we must consider a few points. As agents are forward-looking, they duly foresee higher prices, a fact which pushes the supply curve further up, but not necessarily by the same amount everywhere because they correctly anticipate the domestic price increase; indeed, the theory behind the supply equation (1) makes supply a decreasing function of the expected domestic inflation rate $p_{i t+1}^{e}{ }^{14}$. To figure out the change in expectations $p_{i t+1}^{e}$ in country $i$, one must ideally solve the model thus taking into account two other separate effects.

As regards the demand side, there will be an increase in the nominal interest rate which is proportional to the area-wide change in the expected inflation rate. The ascending straight line in Panel B, representing the rule, shifts upwards by $\left.(1-\rho) \varphi_{p} \Delta p_{t+1}^{e}\right)$ in equation (3). A change in the real interest rate then follows as the result of the combined increase in the nominal interest rate $\left((1-\rho) \varphi_{p} \Delta p_{t+1}^{e}\right.$, in equation (4)) and the increase in the expected domestic inflation rate, i.e. $\left((1-\rho) \varphi_{p} \Delta p_{t+1}^{e}-\Delta p_{i t+1}^{e}\right)>0$. The increase in the real interest rate and the resulting appreciation usually shrinks real demand and squeezes output thus reducing the output gap. The final outcome for one particular country of the adverse common supply shock, is represented in Fig. 3 as a higher inflation rate, a higher interest rate and a lower output gap.

Fig. 3 - A supply shock according the New Keynesian

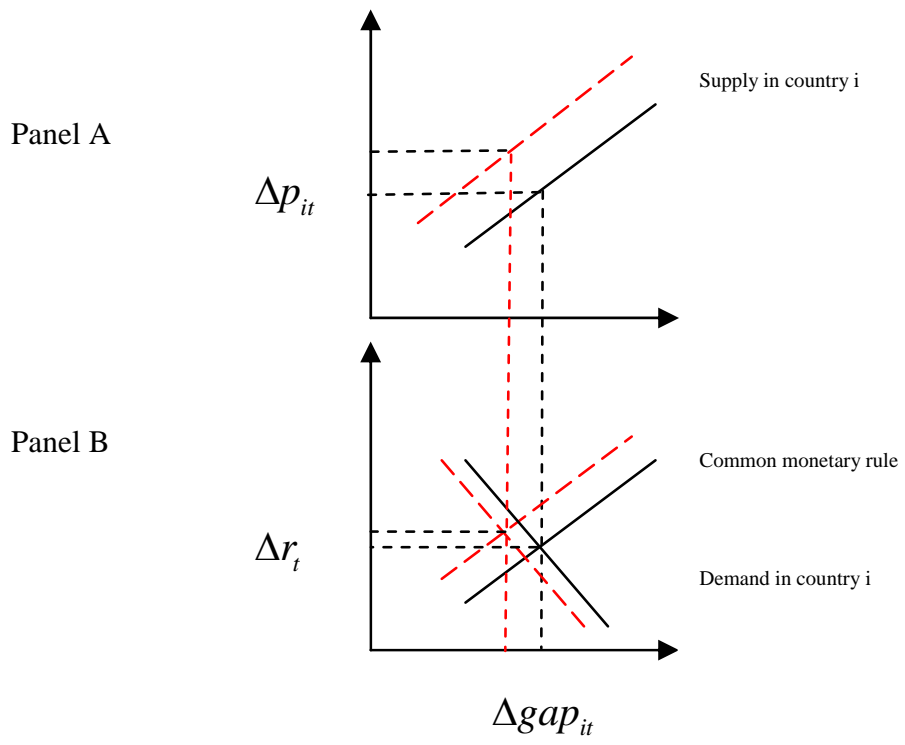

In the case of a monetary union such as the one considered by AE, it is key to understand that while the shift in the monetary rule schedule is the

\footnotetext{
${ }^{14}$ When the current inflation rate $p_{i t}$ is given in equation (1).
} 
same everywhere, the effect on real interest rates and the resulting shift in the demand curves are not the same across space. The final effect on the output gap and the inflation rate therefore cannot be the same everywhere

The crucial feature of a multi-country New Keynesian model such as that of $\mathrm{AE}$ is that the changes in the expected and actual inflation rates (the response profile) are the same in each single country. These differences reflect the limited capacity of the central bank to anchor equally the expected inflation rates across the euro zone, but also the differences existing in the euro zone in the demand and supply equations. Indeed, if agents do not always behave rationally, they can be credited with being able to consider their own country's inflation rate history and prospects, not the area-wide average, as is the case for the ECB. A first potential source of inflation divergence then is the unequal transmission of monetary stimuli across the different countries, as yielded by the parameters $\delta_{i}$, in the $\mathrm{AE}$ model. Integration in European monetary and capital markets is still not perfect, which means that, in a particular country, the perceived real interest rate is different from elsewhere. Furthermore, there are still differences across countries in the degree of persistence. AE assume uniform inflation persistence $\left(\alpha_{1}=0,461\right)$ and the rigidity $(\beta)$ across space, but differences in the degree of persistence and rigidity are nevertheless likely to be important in the euro zone. Finally, the effects of monetary policy which are mediated by the nominal exchange rate of the euro are not the same across the European countries. In conclusion, the changes in the inflation rate and the output gap are different, although the interest rate changes by the same amount, because demand and supply react differently in the different countries.

\section{The money demand equation}

A second way of looking at inflation and growth is based on the aggregate money demand equation. Although the money demand equation can be ascribed to Keynes, it is also compatible with the monetary tradition in that it focuses on the quantity of money made available to agents and the amount they are willing to hold in their portfolios (Friedman, 1970, Brand and Cassola, 2004). What interests us here is that, according to this theory, changes in the level of real output drive changes in the level of prices, given the amount of available liquidity and its circulation velocity. In this case, the relation between the rate of real growth and the rate of inflation is inverse, which means that there is a possibility that a single monetary policy combined with permanent disparities in the rate of growth could be a source of inflation differentials per se, particularly if the euro money market fails to integrate perfectly. This theory offers a way of interpreting the observed differences in inflation across the euro area which is different from that purported by the New Keynesian theory. 
Consider the current money demand in the euro zone. Conventional money demand models assume that real GDP, interest rates and the price level are the determinants of the money that agents want in their portfolios and the recent estimates of the euro-wide money demand equation are no exception. Bruggeman et al., 2003 and Brand - Cassola, 2004, and ECB, 2004, for instance, estimate that a stable long-run demand equation for the whole euro area, such as:

$$
m_{t}=k+\alpha y_{t}-\beta i_{t}
$$

exists; where: $m_{t}$ and $y_{t}$ are logarithms of the real stock of broad money and real GDP, respectively. $k$ is a constant, and $i_{t}$ is the spread between the market interest rate and the rate of return of the money itself, i.e. the opportunity cost of holding liquidity. In the different estimates, it turns out that the elasticity of GDP is always close to 1.3, i.e. $\alpha=1.3$. The estimate of the other parameter is significant, but changes according to the market interest rate used to define the spread. As a matter of fact, it is $-1.8 \leq \beta \leq-0.8$, and in what follows we will assume that $\beta=1.3$ The European Central Bank apparently manages to offer the euro system the right quantity of liquidity in the whole euro area and keep the short term interest rate at the right level. In doing this, it apparently uses, among other things, excess liquidity measures derived from an equation of the type described above, on an aggregate basis. When there are permanent growth disparities inside the euro area and the money market is not perfectly integrated, the aggregate excess liquidity measure cannot signal differences stemming from them, but merely an average difference, and the common monetary policy may lead to inflation disparities across space. This can easily be seen by differentiating the demand equation with respect to time and using the resulting equation to translate the relevant real growth rate into an inflation rate. Let $g_{i}$ and $p_{i}$ indicate, as usual, the real growth and the inflation rates in country $i$. As the long-term rate of growth of the money stock is $n \&=0.045$ (Brand and Cassola, 2004), the equation in terms of percentage rates of changes corresponding to the one defined above is:

$$
p_{i}=0,045-1.3 g_{i},
$$

as it is sensible to assume the spread as a constant, at least in the long run.

Thus, by using this equation, one focuses on the demand side of the economy as the variable driving the inflation rate is real output only. As the ECB assumes that the euro zone has its own single demand equation and the countries do not have one any longer, it is possible to assume that there is only one common inverse relation between the two. Fig. 2 shows the longrun money demand locus which, according to the ECB, holds good in the euro zone. It predicts that when the money stock grows steadily at 4.5 per cent a year, the average inflation rate in the euro zone is a mere 1.9 per cent, 
if the real growth rate is also constant at 2 per cent. As is obvious, an increase in money growth will yield higher inflation, all things being equal. If that relationship between growth and inflation holds good not only for the euro zone as a whole, but also for the single countries, one could say that slow-growing countries would experience inflation rates higher than the average while fast-growing ones would experience inflation rates that are lower than the average, in the long run. But will this happen? According to this theory, the answer will depend on the functioning of the money market. In the wholesale money market, the ECB system supplies liquidity to the banks and to the inter-bank market in the euro zone, while in the national retail markets, households and non-bank institutions apply to local banks. The pattern of inflation rates across the euro zone depends on how this dual market is able to channel liquidity and, thus, on its degree of integration. The target of a flat 2 per cent inflation rate both in slow growers and fast growers can be reached if liquidity can flow through the wholesale market from the retail markets in slow-growing countries, where it is abundant, to where it is scarce, i.e. the retail markets in fast-growing countries, thus allowing countries to lie close or on the long-run demand curve (Fig. 2). The uniform inflation rate could ideally be reached even if real growth were not the same across countries only if the wholesale market were able to channel liquidity as above. The assumption of a common monetary equation does not necessarily imply that the dual market is able to balance supply and demand of liquidity everywhere at the current common interest rate. The ECB is interested in making the internal money market as efficient as possible not only for the sake of making the transmission mechanism as rapid as possible, but also correctly tuned. The ECB itself aims at keeping the area-wide inflation just below $2 \%$ but it would be optimal if all member countries remained constantly at this same mark. In this case, the ECB target could be represented by the horizontal line drawn at $2 \%$. While the money demand locus in Fig. 2 represents the behaviour of the economy in the long-run, the horizontal line indicates the target for the euro zone and for its members. Money market inefficiencies and growth disparities, which are likely to increase in the enlarged euro zone, could bring about the observed disparities in inflation.

At first glance, although the long-run money demand locus in Fig. 2 seems to fit well the pattern of average rates in countries such as Austria, Germany, Belgium, France and Italy, it leaves some outliers (Ireland, Greece, Luxembourg and Spain) and from this point of view it offers a looser data fit than that obtained with the New Keynesian supply curve (Fig. 2).

\section{The Balassa-Samuelson approach}

According to the New Keynesian theory, inflation can be high because high demand interacts with rising costs, accordingly the money demand equation inflation can be high because demand is low, with a given money 
supply. For both theories, high inflation is signalling something wrong in the economy - overheating and rigidities in one case, and excess liquidity in the other. A third view, however, posits that, to some extent, inflation differentials are benign (ECB, 2005). The idea that inflation is proportional to the gap in labour productivity growth of different sectors is also far from new. The so-called Balassa-Samuelson theory consists in the proposition that in any country inflation is proportional to the gap in the productivity growth rates of exportable and non-exportable goods and services, with the corollary that if the country is catching up with the technological frontier in tradable goods, it will necessarily have a higher inflation rate than otherwise. In this case, inflation differentials are benign as they signal a technological catching-up or changes in the economic structure. The model is particularly simple when exchange rates are constant as in a monetary union. By assuming constant income shares and a uniform rate of wage increase $(w)$, the resulting school-book equation for the national domestic rate reads:

$$
p=w-\lambda_{T}+h\left(\lambda_{T}-\lambda_{N}\right),
$$

where the symbols $\lambda_{T}$ and $\lambda_{N}$ indicate the rates of increase in labour productivity in the tradable sector and the non-tradable sector respectively, and the symbol $h$ is the output share of the non-tradable sector. It is immediately clear that any increase in the productivity gap (catching-up in the tradable sector) increases inflation, and vice versa, if $h$ is constant. It is likely that in fast-growing countries a higher rate of increase $\lambda_{T}$ and an even higher rate $w$ add something to the overall inflation rate, even if the increase in the size of the tradable sector reduces the,$h$ thus tempering the catchingup effect itself. The fast growers: Ireland, Luxembourg, Greece and Spain, which have just been labelled as outliers - could not, therefore, be considered as the villains of the euro zone simply because they lie above the ECB target, or out of the money demand locus. More in general, these remarks indicate that the change in the structure and the dynamics in productivity both bear upon the domestic inflation rate ${ }^{15}$.

\section{Synthesis and conclusions}

The annual data regarding real growth and inflation in the euro zone from 1997 to 2005 show both similarities - such as the 2001-2003 slump and differences across countries. Annual data basically seem to show (Fig. 4) a less clear-cut and recurrent New Keynesian pattern of change than what emerges on the basis of average rates (Fig. 2). It would be quite accurate to characterize the 2001-2003 slump and the subsequent changes in the expected inflation rates as a good example of what can shift the supply and demand curves in the different countries. As was the case in the simple

\footnotetext{
${ }^{15}$ In a larger euro zone, integration and structural change will be even more important than now.
} 
example shown in Fig. 3, an adverse shock and the ensuing change in the expected inflation rate force the system to jump from one supply curve to the next. This must be taken into consideration when the New Keynesian model is used. What is most striking when looking at annual data is the existence of countries that float around the cross-over point between the money demand line and the ECB target horizontal line. The cases of Austria, Belgium, France and Germany (Fig. 4, Panel A) not only is one of gravitation towards the ECB target line it is one in which the pattern seems to be well interpreted by the money demand equation and also the result of shifts of the supply curve in the New Keynesian model ${ }^{16}$.

Annual data show that some other countries do not always gravitate towards the cross-over or gravitate differently. Finland started well away from the demand descending line, but it has since reached it and then walked down it (Fig.4, Panel B). Italy hovers just above the target line.

The pattern followed by Portugal, Spain and the Netherlands (Fig. 4, Panel C) is also different from the previous ones. Portugal, Spain and the Netherlands have floated by more distantly but they have recently shown a tendency to converge to the money demand equation.

The case of Portugal and the Netherlands is one of lower stability or, at least, a different way of being stable. The true outliers are Luxembourg, Greece and Ireland (Fig. 4, Panel D). To them we can add Slovenia as it will be in the euro zone as of January 2007. The case of the four countries is not the one predicted by the negative-sloped money demand or the ECB target line, as supply elements - such as those embedded in the New Keynesian theory and the structural model - are slightly more visible in the available statistical records.

In conclusion, we stress that inflation disparities can be better analysed in conjunction with growth disparities because inflation and growth are mutually and strictly dependent phenomena of what we call macroeconomic stability. There are different theories. The models do not always give a role to the stock of money and offer very different predictions about the combined dynamics of real growth and inflation. The annual data for the member countries - while showing some convergence towards the pattern implicit in the area-wide money demand equation - still do not follow a really common pattern.

\footnotetext{
${ }^{16}$ As it is apparent from inspection of the equations in section 4, the New Keynesian model does not assign any explicit role to the stock of money.
} 
Fig. 4 Panel A - Austria, Belgium, France and Germany
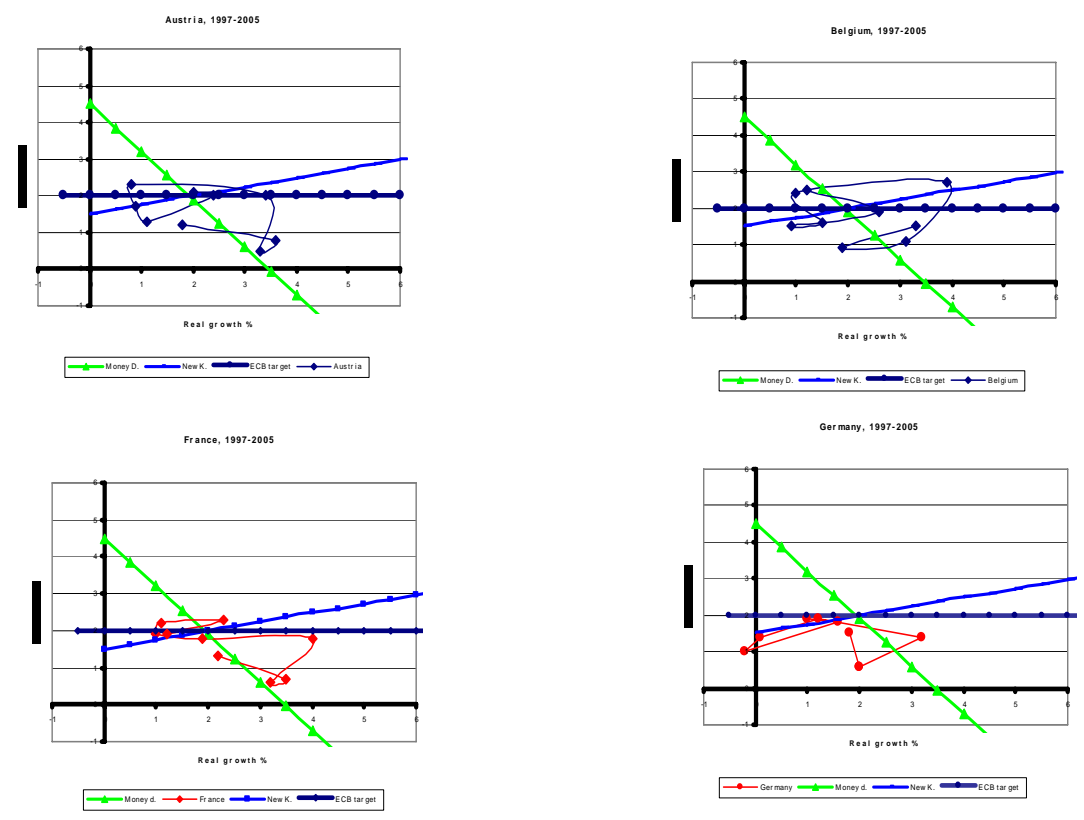
Fig. B - panel B - Italy and Finland

Italy, 1997-2005

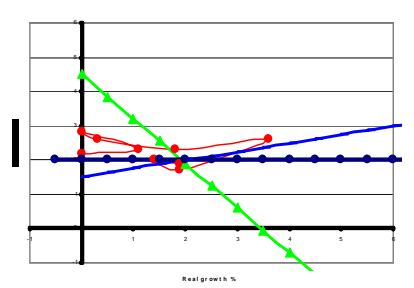

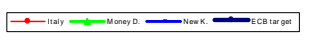

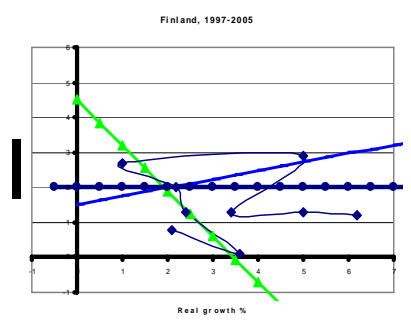

-

Fig. 4, Panel C - Spain, Portugal and Netherlands
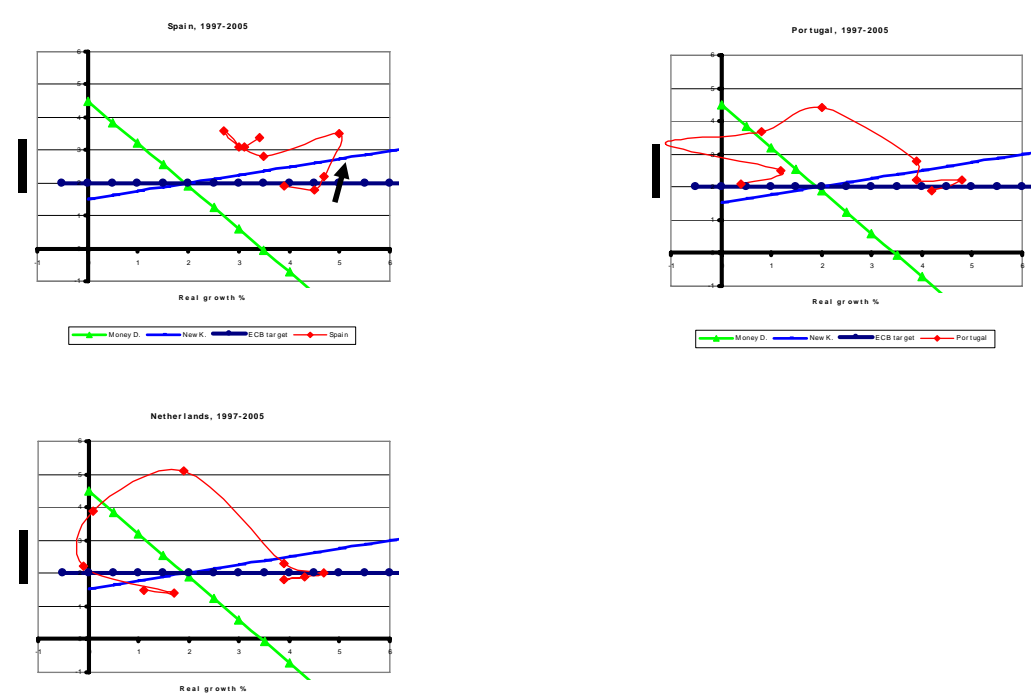

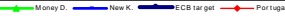

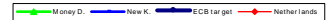


Fig. 4, Panel D - Luxembourg, Greece, Ireland and Slovenia
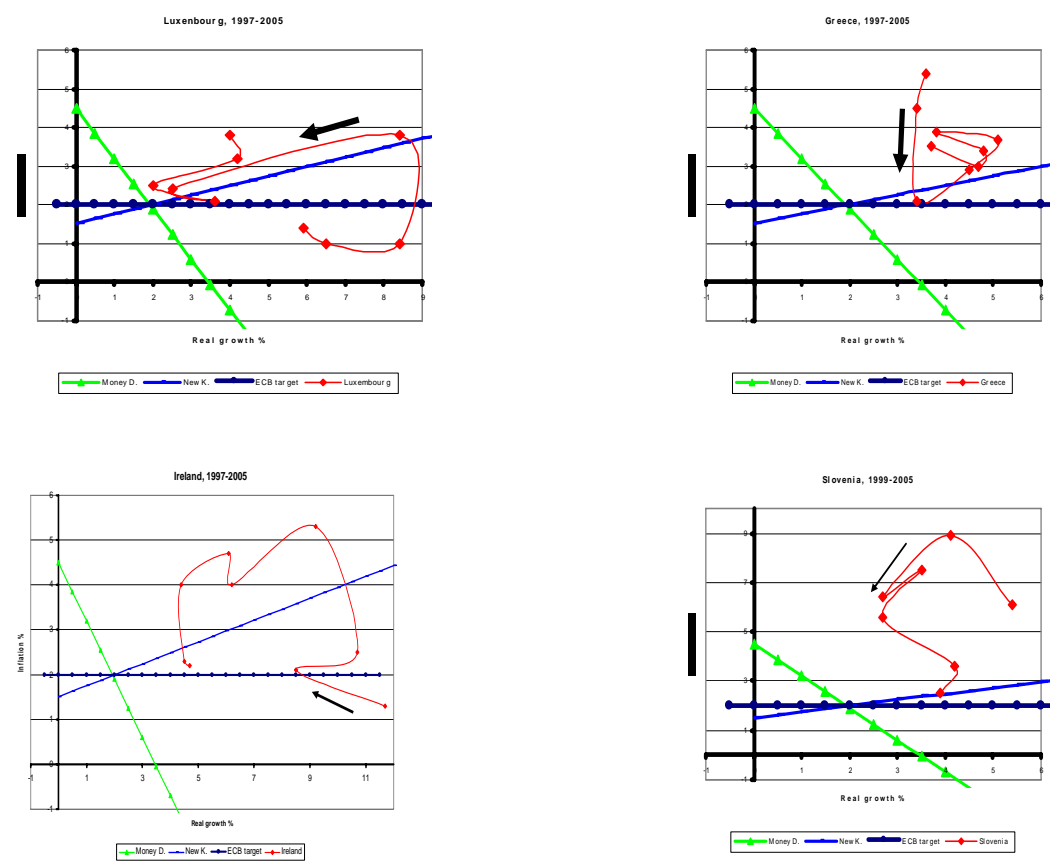


\section{References}

Angeloni I., Ehrmann M. (2004) Euro area inflation differentials. Central Bank Working Paper Series No. 388 (September).

Brand B., Cassola N. (2004) A money demand system for Euro area M3. Applied Economics, 36: 817-838.

Bruggeman A., Donati P., Warne A. (2003) Is the demand for Euro area M3 stable? European Central Bank Working Paper Series No. 255 (September).

Busetti F., Forni L., Harvey A., Venditti F. (2006) Inflation convergence within the European Monetary Union. European Central Bank Working Paper Series No.574 (January).

Buti M., Roeger W., In’t Veld J. (2001) Stabilizing output and inflation: policy conflicts and co-operation under a Stability pact. Journal of Common Market Studies, (Dec), 801-828.

Clarida R., Gali J. , Gertler M. (1999) The science of monetary policy: a New Keynesian perspective. Journal of Economic Literature, 37 (Dec.), 1661-1707.

European Central Bank (2004) Monetary analysis in real time. Monthly Bulletin (October): 42-66.

European Central Bank (2005) Monetary policy and inflation differentials in a heterogeneous currency area. Monthly Bulletin (May): 61-77.

Friedman M. (1970) A Theoretical Framework for Monetary Analysis. Journal of political Economy, 78 (2), 193-238.

Papademos L. D. (2006) Policy-making in EMU: strategies, rules and discretion. Economic Theory, 27 (1), 25-38.

Sapir A. et al. (2004) An agenda for a growing Europe: making the EU system deliver. Report of an independent High-Level Study Group established on the initiative of the President of the European Commission, Bruxelles, July. 